\title{
Can Battlefield Acupuncture Improve Colonoscopy Experience?
}

\author{
Mohamed M. Abdelfatah, MD, ${ }^{1,2}$ Michelle C. Beacham, RN, \\ Michael Freedman, MD, and Hans L. Tillmann, $\mathrm{MD}^{1,2}$
}

\begin{abstract}
Background: Currently, patients undergoing colonoscopy receive sedation, but pain management with acupuncture could be a safer alternative.

Cases: This article describes 3 cases for which Battlefield Acupuncture was applied during colonoscopy to avoid using opioids for sedation. One case was a patient with a life-threating morphine allergy, and 2 other cases avoided sedation completely.

Results: Pain was reduced in all 3 cases to allow completion of colonoscopies without sedation. In Case 2, the patient also gained relief of preexisting mild joint pain.

Conclusions: More data are needed, so potentially more patients can indeed avoid morphine/benzodiazepambased sedation by use of acupuncture to make colonoscopies safer and more pleasant.
\end{abstract}

Keywords: Battlefield Acupuncture, auricular acupuncture, colonoscopy, sedation

\section{INTRODUCTION}

$\mathbf{O}$ PIOID-BASED MODERATE SEDATION has been the standard of care for sedation in most endoscopy units in the United States. Propofol can be used as an alternative but requires anesthesia support. Adverse events from either kind of sedation are not negligible. Moreover, due to the risk of opiates' abuse, use of these drugs should be avoided when feasible.

Alternative approaches for pain management, such as acupuncture, have not yet been widely adopted in the United States, but acupuncture-in the form of auriculotherapy Battlefield Acupuncture (BFA) - has received some acceptance within the military and the Veterans Administration health care system. ${ }^{1,2}$ This specific acupuncture method is based on utilization of up to 5 points on each ear. BFA was developed in the United States by Niemtzow in 2001. ${ }^{3}$ In this intervention, a sequence of cone-shaped gold needles is placed in up to 5 specific sites in one or both ears. Although BFA effectiveness had not been thoroughly validated, ${ }^{4}$ individual experiences- even among critics and also personal experiences-suggest effectiveness in some patients with chronic or acute pain. ${ }^{2,5}$ In recent years BFA has been taught more widely and applied in the military and the VA health care systems. ${ }^{1,2}$

This article presents 3 cases in which BFA enabled completion of colonoscopies with reduced or no sedation; first in a patient with a life-threatening morphine allergy, and, subsequently, in 2 patients to substitute completely for moderate sedation. All patients gave oral consent to undergo BFA during the procedure, and BFA was applied when some pain emerged during the procedure.

\section{CASES}

\section{Case 1}

The first case was a 55-year-old veteran with a history of allergy to morphine to the extent of asystole. He was

\footnotetext{
${ }^{1}$ Greenville Veterans Administration Health Care Center, Greenville, NC.

${ }^{2}$ Division of Gastroenterology, Hepatology and Nutrition, Department of Medicine, East Carolina University, Greenville, NC.

The views expressed in this manuscript are those of the authors and do not necessary reflect the official policy or position of the Department of Veteran Affairs, nor the United States government.
} 
scheduled for colonoscopy in the summer of 2017. He was unable to find a driver willing to bring him to a more-distant location, where sedation with propofol could be offered. Moreover, the usual sedation with the combination of midazolam and fentanyl was not felt to be safe regarding fentanyl, due to his history of asystolic reaction to morphine.

Thus, it was suggested to use midazolam and diphenhydramine for sedation and use BFA for pain management during the procedure, instead of typical pain management with fentanyl.

The patient was sedated with midazolam, and that sedation was augmented with $50 \mathrm{mg}$ of diphenhydramine. During the procedure, he received a total of $7 \mathrm{mg}$ of midazolam, and repeatedly expressed having pain by severe grimacing; thus twice, a single Aiguille Semi-Permanente (ASP), semipermanent, gold-plated acupuncture needle (ASP ${ }^{\circledR}$ original, Sedatelec, ${ }^{\circledR}$ F-69540, Irigny, France) was placed. The first one was placed at the Cingulate Gyrus (point 1) of the right ear and the second one was placed at the Thalamus (point 2) of the right ear. Because the patient was positioned on the left side, the right ear had been chosen for BFA application. Each time, the patient seemed to have some pain relief, as noted by his reduced grimacing. This approach allowed completion of the procedure, including ileum intubation.

\section{Case 2}

Seven months later, a 66-year-old male veteran presented for a colonoscopy with standard sedation consisting of midazolam and fentanyl for polyp surveillance. Four years earlier, he had had an initial colonoscopy; at that time, he had required $4 \mathrm{mg}$ midazolam, $100 \mu \mathrm{g}$ of fentanyl, and $50 \mathrm{mg}$ of diphenhydramine for sedation.

The patient arrived without a driver, and thus, it was not possible to offer him sedation. Due to more successful experiences with BFA for chronic pain management in the clinic at this point, and the positive experience with Case 1, the patient was offered the option of having the colonoscopy completed with acupuncture administered for pain relief. Otherwise, he would have needed to reschedule and drink the colonoscopy preparation again. He was more interested in trying to proceed with acupuncture versus canceling and rescheduling his procedure, with the requirement to drink the preparation for the colonoscopy again.

During the procedure, the patient felt discomfort once the sigmoid level was reached; thus, two Pyonex ${ }^{\mathrm{tm}}$ acupuncture needles (Seirin Corporation, Shizuoka, Japan) were placed at the Cingulate Gyrus (point 1) and the Thalamus (point 2) of the right ear. Due to his being positioned on his left side, the right ear was more easily accessible. Immediately after placement, the patient reported reduction of his pain: His pain was reduced from $10 / 10$ to $0 / 10$. This enabled completion of colonoscopy, including ileum intubation and resection of 4 identified polyps. This patient was comfortable throughout the remaining procedure, which, due to the polyp resections, required a total procedure time of 40 minutes.
Furthermore, due to lack of sedation, the patient was allowed to drive and resume his daily activity. As an additional benefit, his preexisting mild joint pain of $1 / 10$ had dropped to $0 / 10$ following the acupuncture.

\section{Case 3}

A 66-year-old male presented for surveillance colonoscopy due to a personal history of tubular adenoma 5 years ago. He reported prolonged drowsiness - attributed to sedationwhen he underwent his previous colonoscopy. Given the positive experience in the 2 previous patients, this new patient was offered acupuncture as an alternative to sedation with a plan to switch to moderate sedation if he experienced any discomfort for which he preferred moderate sedation. He preferred to try the acupuncture.

During the procedure, the patient felt some discomfort when the level of the sigmoid was reached. Thus, Pyonex acupuncture needles were placed at the point Cingulate Gyrus (point 1) and the Thalamus (point 2) of the right ear. Again, due to patient being positioned on the left side, the right ear was more accessible for acupuncture during the procedure. Immediately after placement of the acupuncture needles, he reported reduction of his pain. Twice, this patient reported a pain increase to $6 / 10$ during the procedure. This pain immediately dropped to a $2 / 10$ in response to the application of BFA. This enabled completion of the colonoscopy, including ileum intubation and resection of 3 identified polyps without the need for sedation. The patient remained comfortable throughout the 35 minutes of the procedure.

\section{RESULTS}

As noted above, pain was reduced in all 3 cases and the colonoscopies were completed without sedation. In Case 2, the patient also gained relief of preexisting mild joint pain.

\section{DISCUSSION}

For these 3 cases of elective colonoscopy-including polypectomy-use of acupuncture resulted in successful completion of required procedures that otherwise might not have been completed. Postprocedure surveys were consistent with great patient satisfaction among these patients. Moreover, the turnover time and the postprocedure observation time was markedly lower than colonoscopy with moderate sedation.

While all 3 patients underwent colonoscopies due to varying degrees of medical necessity-morphine allergy in the first, absence of an escort in the second, and wish to avoid drowsiness from sedation in the third-the demonstrated feasibility of using acupuncture for pain management during 
colonoscopy suggests that this approach could potentially be used more broadly to minimize sedation. BFA allows patients to be fully functional immediately after a procedure. Furthermore, the lack of sedation makes procedures safer and allows for maintained communication between providers and patients.

Albeit the validity of acupuncture for medical intervention is still early, a randomized controlled trial by MacPherson et al. from the United Kingdom. found that acupuncture use in patients with irritable bowel syndrome resulted in reduction of symptoms at 3,6 , and 12 months postrandomization. ${ }^{6}$ Importantly, adverse events of acupuncture were extremely rare. ${ }^{7-11}$

\section{CONCLUSIONS}

The successful utilization of BFA for colonoscopy presented here justifies further study on BFA as a safe and effective way to improve patient experiences associated with colonoscopies.

\section{ACKNOWLEDGMENTS}

H.L.T. appreciates greatly that the Veterans Affairs Administration allowed him to learn BFA.

The authors want to acknowledge the supportive nursing and technical support staff in the Endoscopy unit: Stacie S. Kirkman, RN, Denise K. Maxey, RN, Donna McAdam, RN, W. Paul McMillen, RN, Robin DiDonato, RN, Joseph Burless, ST, and Christopher Crumedy, ST.

\section{FUNDING SOURCE}

No funding was received other than VA employment salary. Patient care was provided as part of employment. The article was written during "off-time," which included breaks and after hours.

\section{AUTHOR DISCLOSURE STATEMENT}

No competing financial interests exist.

\section{REFERENCES}

1. Madsen C, Patel A, Vaughan M, Koehlmoos T. Use of acupuncture in the United States military healthcare system. Med Acupunct. 2018;30(1):33-38.

2. Federman DG, Gunderson CG. Battlefield Acupuncture: Is it ready for widespread dissemination? South Med J. 2017; 110(1):55-57.

3. Niemtzow RC. Battlefield Acupuncture. Med Acupunct. 2007; 19(4):225-284.

4. Jan AL, Aldridge ES, Rogers IR, Visser EJ, Bulsara MK, Niemtzow RC. Does ear acupuncture have a role for pain relief in the emergency setting? A systematic review and meta-analysis. Med Acupunct. 2017;29(5):276-289.

5. Federman DG. On "Battlefield Acupuncture: Is It Ready for Widespread Dissemination?" South Med J. 2017;110(5):392.

6. MacPherson H, White A, Cummings M, Jobst K, Rose K, Niemtzow R; STRICTA Group. Standards for Reporting Interventions in Controlled Trials of Acupuncture: The STRICTA recommendations. J Altern Complement Med. 2002;8(1): 85-89.

7. White A, Hayhoe S, Hart A, Ernst E. Adverse events following acupuncture: Prospective survey of 32000 consultations with doctors and physiotherapists. BMJ. 2001;323(7311): 485-486.

8. Melchart D, Weidenhammer W, Streng A, et al. Prospective investigation of adverse effects of acupuncture in 97733 patients. Arch Intern Med. 2004;164(1):104-105.

9. Forbes A, Jackson S, Walter C, Quraishi S, Jacyna M, Pitcher M. Acupuncture for irritable bowel syndrome: A blinded placebo-controlled trial. World J Gastroenterol. 2005;11(26):4040-4044.

10. Reynolds JA, Bland JM, MacPherson H. Acupuncture for irritable bowel syndrome- $\mathrm{n}$ exploratory randomised controlled trial. Acupunct Med. 2008;26(1):8-16.

11. Anastasi JK, McMahon DJ, Kim GH. Symptom management for irritable bowel syndrome: A pilot randomized controlled trial of acupuncture/moxibustion. Gastroenterol Nurs. 2009; 32(4):243-255.

Address correspondence to:

Hans L. Tillmann, MD

Greenville Veterans Administration Health Care Center 401 Moye Boulevard Greenville, NC 27834

E-mail:Tillmannh14@ecu.edu 